\title{
REDE SOCIAL E VÍNCULOS APOIADORES DAS FAMÍLIAS DE CRIANÇAS COM CÂNCER ${ }^{1}$
}

\author{
Aline Oliveira Di Primio ${ }^{2}$, Eda Schwartz ${ }^{3}$, Valquíria de Lourdes Machado Bielemann ${ }^{4}$, Andréia Burille \\ Juliana Graciela Vestena Zillmer ${ }^{6}$, Aline Machado Feijó
}

\footnotetext{
${ }^{1}$ Trabalho de Conclusão de Curso de Graduação da Faculdade de Enfermagem e Obstetrícia da Universidade Federal de Pelotas (UFPel).

${ }^{2}$ Enfermeira. Enfermeira do Hospital do Município de Jaguarão-RS. Rio Grande do Sul, Brasil. Email: alinediprimio@hotmail.com

${ }^{3}$ Doutora em Enfermagem. Docente da Faculdade de Enfermagem e Obstetrícia (Feo) da UFPel. Rio Grande do Sul, Brasil. Email: eschwartz@terra.com

${ }^{4}$ Mestre em enfermagem. Rio Grande do Sul, Brasil. Email: valvmb@gmail.com

${ }^{5}$ Acadêmica do Curso de Enfermagem da Feo-UFPel. Bolsista de iniciação científica. Rio Grande do Sul, Brasil. Email: andreiaburille@yahoo.com.br

${ }^{6}$ Mestranda do Programa de Pós Graduação em Enfermagem da UFPel. Rio Grande do Sul, Brasil. Email: juzillmer@hotmail.com

${ }^{7}$ Mestranda do Programa de Pós Graduação em Enfermagem da UFPel. Rio Grande do Sul, Brasil. Email: aline_feijo@yahoo. com.br
}

RESUMO: O estudo buscou conhecer os vínculos apoiadores e a rede social das famílias que têm em seu contexto uma criança com câncer. Trata-se de uma investigação exploratória, descritiva, com abordagem qualitativa. Participaram do estudo seis familiares, sendo dois de cada uma das crianças com câncer internadas na Unidade Onco-Hematologia do Hospital Infantil Joana de Gusmão Florianópolis-SC. A coleta de dados foi realizada através de entrevista semiestruturada, de maio a junho de 2006. Para organização dos resultados foi utilizada a análise temática. Os resultados revelam que a família procura se organizar para lidar com a doença, gerando um fortalecimento dos vínculos familiares e da rede de apoio. A religiosidade aparece como estratégia para suportar as situações advindas do câncer. Entretanto, evidenciou-se que a doença também pode fragilizar os vínculos anteriormente estabelecidos.

DESCRITORES: Família. Criança. Câncer. Enfermagem. Apoio social.

\section{SOCIAL NETWORK AND SUPPORT BONDS OF THE FAMILIES OF CHILDREN WITH CANCER}

\begin{abstract}
This study sought to know the support bonds and the social network of the families that have a child with cancer in their context. It is an exploratory, descriptive investigation made with a qualitative approach. Six family members participated in the study, two from each of the children with cancer hospitalized in the Onco-Hematology Unit of the Joana de Gusmão Children's Hospital in Florianópolis, Santa Catarina, Brazil. The data was collected using semi-structured interviews carried out from May to June of 2006. In order to organize the results, thematic analysis was used. The results revealed that the family seeks to organize itself in order to deal with the disease, resulting in a strengthening of family bonds and respective support networks. Religion appears as a strategy to handle situations which arise from cancer. However, it became clear that the disease can also weaken the previously established bonds.
\end{abstract}

DESCRIPTORS: Family. Child. Cancer. Nursing. Social support.

\section{LOS VÍNCULOS Y LA RED DE APOYO SOCIAL A LAS FAMILIAS DE NIÑOS CON CÁNCER}

RESUMEN: El estudio tuvo como objetivo conocer los vínculos y la red de apoyo social a las familias que tienen un niño con cáncer. Se trata de una investigación exploratoria, descriptiva con enfoque cualitativo. Los participantes del estudio son seis familiares, dos de cada uno de los niños con cáncer hospitalizados en la Unidad de Oncología y Hematología del Hospital Infantil Joana de Gusmão, Florianópolis, Santa Catarina, Brasil. La recolección de datos se realizó a través de entrevista semiestructurada, de mayo a junio de 2006. Para la organización de los resultados se utilizó el análisis temático. Los resultados muestran que la familia intenta organizarse para hacer frente a la enfermedad, dando lugar a un fortalecimiento de los lazos familiares y la red de apoyo. La religiosidad aparece como una estrategia para manejar las situaciones derivadas del cáncer. Sin embargo, quedó claro que la enfermedad también puede debilitar los vínculos establecidos previamente.

DESCRIPTORES: Familia. Niño pequeño. Câncer. Enfermería. Apoyo social. 


\section{INTRODUÇÃO}

Na sociedade, o câncer é visto como uma doença que gera sofrimento, dor e desestruturação familiar, e esses sentimentos se intensificam quando se trata de uma criança, pois ela está iniciando sua trajetória de vida. Dessa forma, a família assume um importante papel no cuidado à criança, pois detém a responsabilidade com o bem-estar físico, emocional e social de seus membros, e é no reduto familiar que a criança encontra boa parte de seu referencial. ${ }^{1}$

A fragilidade que uma doença crônica, como o câncer, impõe ao viver das famílias, considerando as intercorrências no decorrer do tratamento quimioterápico, repercute em como a criança será tratada e enfrentará seu adoecimento e tratamento. ${ }^{2}$ Nesse sentido, o tratamento para o câncer, em si, é tão importante quanto a atenção dispensada aos aspectos sociais da doença. Desse modo, no encontro com a doença, a criança e a família necessitam receber apoio, o que envolve o comprometimento de uma equipe multiprofissional e a relação com diferentes setores da sociedade. ${ }^{3}$

As nossas vivências, ao assistir famílias, nos possibilitaram entender que o paciente é um seguimento da família, e que esta é de vital importância para a recuperação de sua saúde. Desse modo, os profissionais de saúde necessitam conhecer a estrutura familiar, sua dinâmica e as interações que essa família possui e estabelece nos contextos em que transita, para assim atender a suas reais necessidades, buscando fortalecer e manter os vínculos apoiadores.

Em consonância com as concepções e reflexões deste estudo, escolheram-se os conceitos de vínculo apoiador e de rede social de Urie Bronfenbrenner. Define-se como vínculo apoiador aquela pessoa que poderá participar de dois ou mais sistemas, formando um elo, o que facilita o processo de resolução das crises desenvolvimentais geradas pela e na família. A rede social é descrita como um sistema de interação sequencial formada por pessoas que podem apoiar, mesmo sem que a pessoa em desenvolvimento esteja presente. ${ }^{4}$

Diante do exposto, refletimos acerca das famílias que possuem uma criança com câncer e isto nos instigou a questionar como tais famílias lidam com a situação de adoecer, quais são os vínculos apoiadores e as redes sociais formadas por elas. Sabemos que muitas famílias deixam suas casas para acompanhar o tratamento da criança no hospital, e é nessa hora que os vizinhos, os amigos unem-se à família para apoiá-la, constituindo-se numa importante e extensa rede social.
Dessa forma, considera-se de extrema relevância que o enfermeiro e demais profissionais conheçam a rede social e os vínculos apoiadores, pois a partir disso poderão se utilizar dos mesmos para intensificar o cuidado à família e à criança com câncer. Além disso, com este estudo busca-se reforçar e ampliar o conhecimento científico dos profissionais de saúde, com vistas à qualificação da assistência no cuidar da família que possui em seu contexto uma criança com câncer, no decorrer de todo o processo de adoecer e do tratamento. A partir do exposto, o estudo teve como objetivo conhecer os vínculos apoiadores e as redes sociais formadas pelas famílias que têm em seu contexto uma criança com diagnóstico de câncer.

\section{METODOLOGIA}

Trata-se de uma investigação exploratória, descritiva, com abordagem qualitativa. O cenário da pesquisa foi a Unidade Onco-Hematologia do Hospital Infantil Joana de Gusmão, no Município de Florianópolis, do estado de Santa Catarina.

Para o desenvolvimento do estudo, consideraram-se os seguintes critérios de inclusão das famílias: ter uma criança com câncer; estar ciente do diagnóstico e tratamento, e a criança estar em tratamento quimioterápico. Os sujeitos da pesquisa foram seis familiares, sendo dois de cada uma das crianças portadoras de câncer. A coleta de dados se realizou no período de maio a junho de 2006. Como instrumentos de coleta de dados foram utilizados a entrevista semiestruturada, o genograma e o ecomapa.

O genograma é uma árvore que representa a estrutura familiar interna, e o ecomapa é a representação visual dos relacionamentos entre os membros da família e os sistemas mais amplos. Eles possibilitam a percepção de toda a família, delineando sua natureza, as interfaces e pontos de intermediação, pontes a construir e recursos a serem buscados e mobilizados para atuar nos conflitos. ${ }^{5}$ Além disso, apresentam outros aspectos positivos, como a facilitação da abordagem entre o entrevistador e o entrevistado; a visualização de maneira objetiva das relações intra e extrafamiliares; a evidência e a discussão de alternativas de mudanças na família; a identificação de características comuns e singulares de cada pessoa da família e a possibilidade do entrevistado manifestar-se através da linguagem não-verbal. ${ }^{6}$ No presente estudo, o genograma e ecomapa foram construídos juntamente com dois familiares de cada uma das crianças com câncer. Nessa ocasião, os familiares resgataram pessoas e momentos históricos da família. 
A entrevista semiestruturada obedece a um roteiro de questões abertas e fechadas, permitindo ao pesquisador maior abrangência do assunto. ${ }^{7}$ As entrevistas foram previamente agendadas e acordadas com os familiares, e aconteceram em uma sala reservada do próprio hospital. Com o consentimento dos familiares, elas foram gravadas; tiveram duração em média de uma hora, sendo posteriormente transcritas na íntegra. Para a análise dos dados, adotou-se a análise temática. ${ }^{7}$

O projeto foi aprovado pelo Comitê de Ética em Pesquisa do Hospital Infantil Joana de Gusmão, sob protocolo n ${ }^{\circ}$ 017/2006, segundo os princípios e a Resolução do Conselho Nacional de Saúde n ${ }^{\circ}$ 196/96. Os sujeitos concordaram em participar do estudo e deram anuência no Termo de Consentimento Livre e Informado. Para manter o sigilo e o anonimato, buscamos preservar a identidade dos familiares, identificando-os por nomes próprios escolhidos pelos mesmos.

\section{RESULTADOS E DISCUSSÃO}

\section{Apresentando as famílias}

Família de Rafael (Figura 1) - Rafael, 10 anos, diagnóstico de Leucemia Linfocítica Aguda. Após seis meses de alta, retornou ao hospital, com recidiva em testículo direito e medula óssea, para intervenção cirúrgica e tratamento quimioterápico. Sua mãe Luana, 33 anos, era casada, possuía quatro filhos. Trabalhava como diarista, mas naquele momento não estava trabalhando devido ao tratamento do filho, mesmo assim, mantinha contato com as famílias para quem trabalhava. Ela tinha a sua mãe (Laura), seu marido e uma amiga para os momentos em que precisava desabafar. Rompeu o vínculo com a igreja evangélica, pois eles não ofereceram apoio no início da doença, mas acreditava em Deus. Luana, quando não estava no hospital, tentava se distrair fazendo crochê, visitando amigos e também pesquisando na Internet, onde se atualizava sobre o tratamento da leucemia. No hospital, relacionava-se bem com a equipe de saúde e também com as colegas de quarto. Ela sempre busca conhecer pessoas que estavam vivenciando a mesma situação e, através dessa interação, se fortalecia. Laura, 56 anos (mãe de Luana e avó do Rafael) era casada e evangélica praticante. Trabalhava como empregada doméstica há sete anos na mesma casa, e mantinha ótima relação com sua patroa. Laura morava com seu marido (ex-alcoólatra) e seu filho mais novo (usuário de drogas), tinha uma relação bastante conflituosa com o marido, pois este não aceitava que ela ajudasse o filho drogadito e também por ele (marido) ser uma pessoa bastante hostil. O lazer de Laura era visitar seus filhos e ir às congregações da igreja. Os finais de semana ela passava no hospital com seu neto, para que sua filha pudesse ir para casa ficar com os outros filhos. Apesar do pouco convívio com a equipe de saúde, mantinha boa relação com ela.

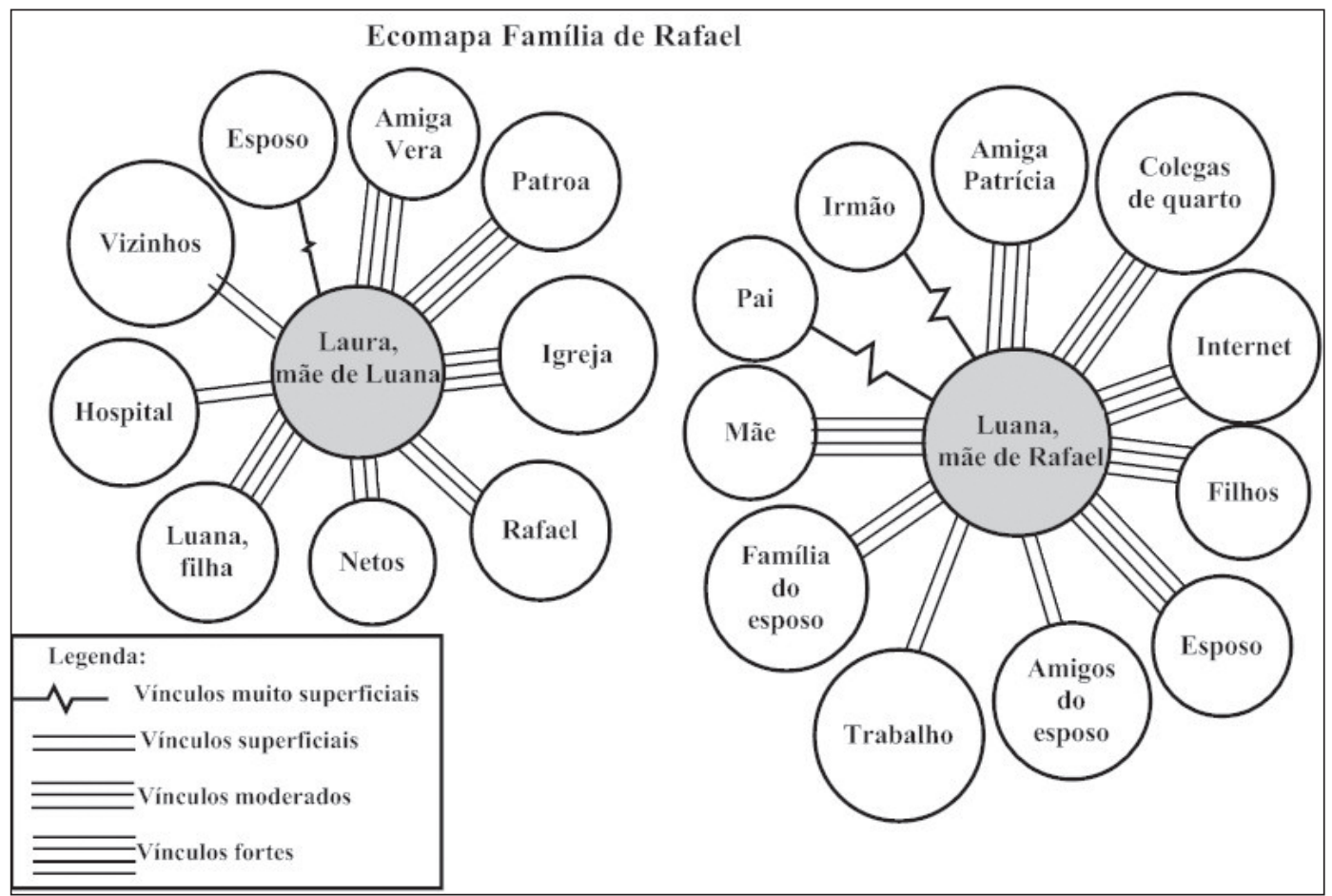

Figura 1 - Representação gráfica do ecomapa da família de Rafael 
Família de Gabriel (Figura 2) - Gabriel, oito meses, diagnóstico de Meduloblastoma. Internado pela primeira vez na unidade para realização de quimioterapia. Sua mãe Alice, 25 anos, casada, tinha dois filhos, relatou que Gabriel começou a apresentar alguns sintomas da doença aos cinco meses de idade. Achando estranho, Alice buscou auxílio profissional e depois de vários exames recebeu o diagnóstico. Alice mostrava-se esperançosa em relação ao tratamento, mesmo sabendo do quadro grave de seu filho. Em nenhum momento desanimou, sempre esteve presente, ajudando nos cuidados, dispensando carinho e atenção ao filho. Tinha sua mãe como o único vínculo apoiador na família, mas não estava conversando muito com ela, para não sobrecarregá-la, já que ela estava cuidando de seu outro filho. A relação com o marido desde o início da doença ficou estremecida, pois este não gostava do ambiente hospitalar e não a acompanhava. Ela era evangélica praticante e mantinha boa relação com a igreja. Depois de sete anos trabalhando como balconista de um supermercado, resolveu parar de trabalhar para se dedicar ao tratamento de seu filho. Ema (irmã de Alice), 27 anos, casada, não tinha filhos devido à histerectomia que sofreu por um tumor benigno no útero. Ela e o marido tinham planos de adotar uma criança e estavam inscritos no programa de adoção da sua cidade. Trabalhou por anos em uma gráfica e resolveu parar de trabalhar e dedicar-se mais a si mesma, mas seguiu mantendo vínculo com sua ex-patroa e com um ex-colega de trabalho. No momento era vendedora de produtos através de revistas. Ema era evangélica praticante, com bom vínculo religioso. Sempre que podia, estava no hospital com sua irmã, dando carinho a seu sobrinho, bem como às outras crianças do quarto. Era uma pessoa muito solidária e preocupada com o sobrinho. Durante o tempo em que esteve no hospital manteve boa relação com a equipe de saúde.

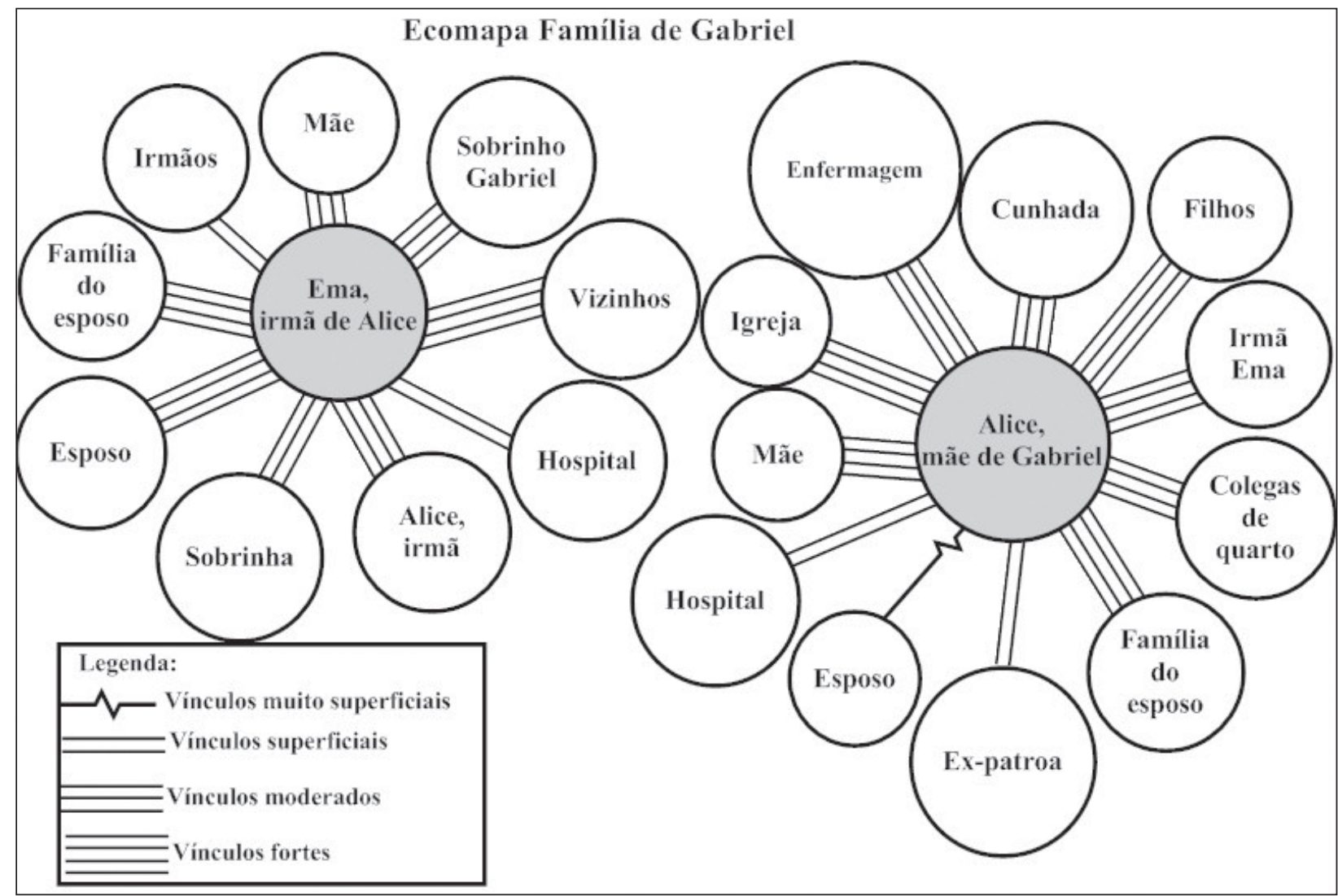

Figura 2 - Representação gráfica do ecomapa da família de Gabriel

Família de Miguel (Figura 3) - Miguel, 10 anos, diagnóstico de Leucemia Linfocítica Aguda, internado pela primeira vez na unidade para iniciar a quimioterapia. Seu pai João, 43 anos, casado, possuía três filhos, era católico não praticante. Tra- balhava em uma oficina de chapeação, da qual era o proprietário, junto com seus filhos mais velhos. Considerava a mãe e os irmãos como uma fonte de apoio. Os amigos estavam sempre oferecendo ajuda, mas João preferia contar com o apoio apenas da fa- 
mília, apesar de achar importante a preocupação dos amigos. Por não ser de Florianópolis, João só ficava no hospital nos finais de semana. Durante o tempo que permaneceu junto ao filho no hospital, manteve sempre boa relação com a equipe de saúde. Eva (mãe de Miguel), 38 anos, possuía três filhos, era católica não praticante. Trabalhava em duas escolas como pedagoga. Ela se declarava como pessoa de poucas amizades, mesmo assim os colegas de trabalho estavam sempre oferecendo ajuda. Sua mãe e sogra eram suas fontes de apoio, bem como a psicóloga, que proporcionou suporte desde os primeiros dias no hospital. Na sua comunidade, mantinha um relacionamento muito superficial com seus vizinhos, não possuía conflitos com ninguém, mas procurava manter relações apenas com seus familiares.

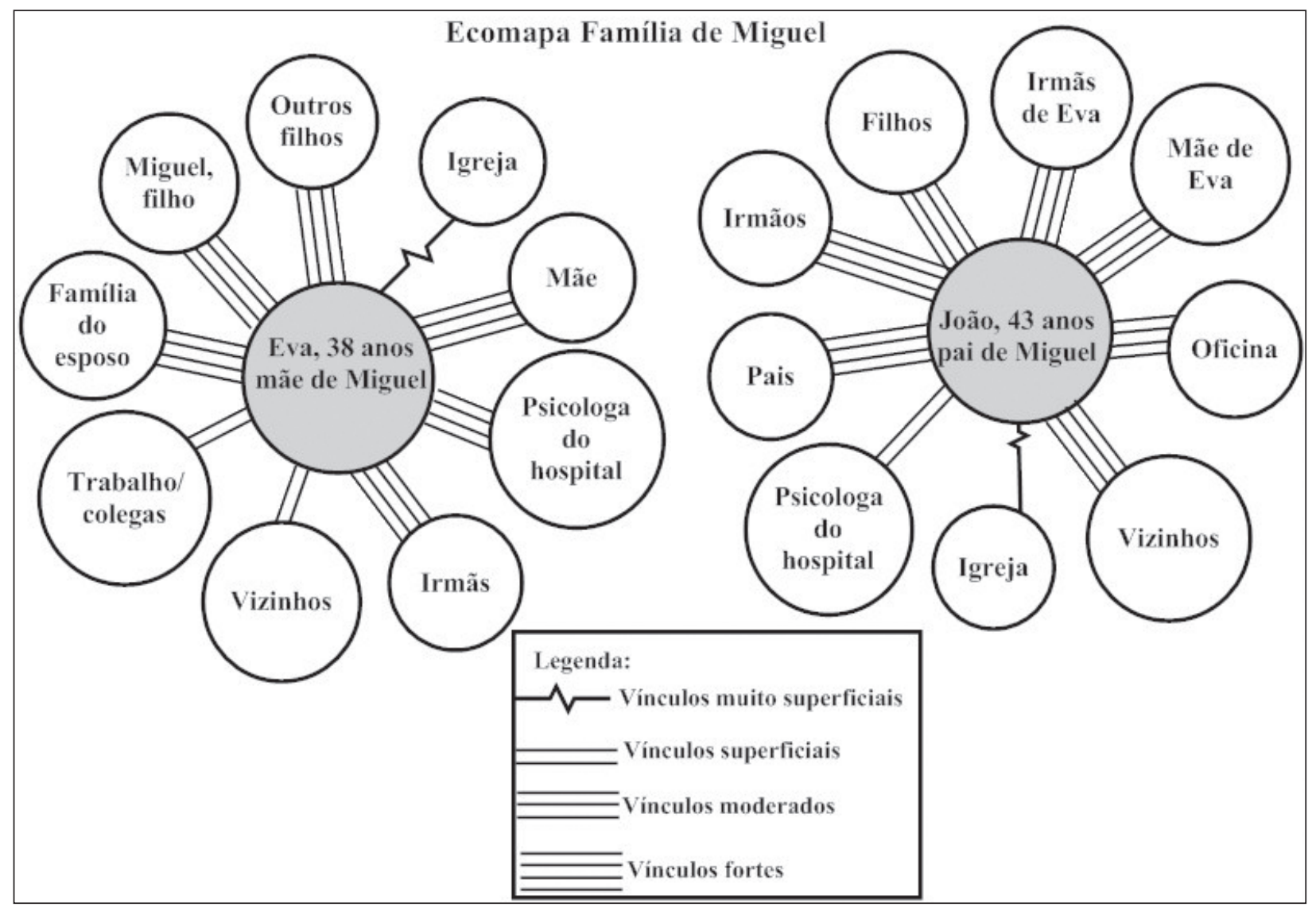

Figura 3 - Representação gráfica do ecomapa da família de Miguel

\section{O fortalecimento dos vínculos apoiadores com a doença}

Verificamos que a família constitui um elo importante para os familiares que estão vivenciando a situação de doença, enfatizando a importância do apoio da mesma para a manutenção do tratamento e do bem-estar dos seus integrantes. Os relatos dos familiares revelam o fortalecimento dos vínculos, principalmente no âmbito familiar. Constatamos que quando um membro da família, neste caso a criança, é acometida por uma doença, a família em si exerce a função de proporcionar recursos físicos e também emocionais para manter a saúde e um sistema de apoio tão necessário nesse momento.
Desse modo, podemos dizer que o câncer na criança modificou a dinâmica e as relações, o que uniu as pessoas da família e fez com que elas se mobilizassem para acolhê-la.

Depois que o Rafael ficou doente, meu marido se chegou mais, principalmente com minha filha (mãe do Rafael) e também com o próprio Rafael [...] ele não era muito sociável (Laura, avó do Rafael).

Tenho um irmão que mora a 300 metros e, se eu o visitei três vezes este ano, foi muito. Depois que o Miguel adoeceu, estou vendo os meus irmãos mais seguido (João, pai do Miguel).

Após a descoberta da doença, a família se uniu muito, tanto meus irmãos quanto meus cunhados (Eva, mãe do Miguel). 
A família se uniu mais. Nós temos uma irmã de Curitiba, ela veio para cá só para ficar revezando comigo aqui no hospital. Até meus irmãos homens se uniram mais (Ema, tia do Gabriel).

O depoimento tanto de Laura (avó de Rafael), como de João (pai de Miguel) explicitam que o câncer fortalece os vínculos à medida que a família relata tanto aproximação física, quanto afetiva. Destacamos também a fala de Luana, pois ela traduz que a doença unifica, e os conflitos ficam em segundo plano, sendo que as pessoas tornam-se mais flexíveis, possibilitando uma aproximação e estabelecimento de um processo comunicativo, evidenciando ser um vínculo fortalecido.

Além disso, a doença fez com que a família se aproximasse justamente no momento em que as relações familiares são fundamentais, promovendo, assim, uma reestruturação da família. A situação de doença é inesperada e afeta tanto a pessoa com câncer, quanto sua família, pois surgem desadaptações e arranjos familiares. Diante disso, a família se mobiliza para manter seu funcionamento e cria uma nova estrutura, para adaptar-se à realidade que se apresenta. Assim, começa a conviver com uma situação em que o doente é o foco da atenção e o funcionamento da família passa a girar em torno dele. ${ }^{8}$

A presença dos familiares promove e mantém a inter-relação criança/família, neutraliza os efeitos decorrentes da separação, colabora na assistência integral, melhora a adaptação ao hospital, facilita a aceitação do tratamento, promove a positiva resposta terapêutica. ${ }^{9}$ Sendo assim, os pais exercem papel fundamental no contexto da hospitalização, na medida em que representam a referência da criança, como mediadores da relação terapêutica, fonte principal de segurança e de carinho, além de um apoio imprescindível ao enfrentamento dessa situação. ${ }^{10}$

O câncer, além de unificar a família, faz com que os seus integrantes tenham um novo olhar sobre si e sobre os vínculos afetivos. Assim, antigos valores, como bens materiais, cedem espaço para novos valores, como saúde e união. A partir da agregação destes novos valores, a família começa a perceber a vida de outra forma, onde o que era valorizado materialmente agora perde o seu significado. Portanto, a percepção da vida familiar anterior à doença é assinalada no relato das famílias sobre as atividades cotidianas, suas relações e uma nova valorização sobre situações vividas.

A gente não fica tão egoísta, não fica pensando: quero isso, aquilo... Agora para mim nada mais importa. Se eu tivesse que dar tudo para o Gabriel sair bem, eu daria (Alice, mãe do Gabriel).
O material você tem hoje. Se você não tem, tudo bem! Para onde você vai, não leva nada. A família é a coisa mais importante que tenho na vida (Ema, tia do Gabriel).

Quando não estou no hospital, aproveito cada minuto que passa ao lado dos meus outros filhos. Antes eu pensava no bem material (Luana, mãe do Rafael).

Ao receber o diagnóstico de câncer na criança, a família busca analisar seus valores, crenças e atitudes, e passa, a partir de então, a ver a vida sob outro enfoque. ${ }^{11}$ Este encontro com a doença proporciona uma reflexão acerca da vida e da situação vivenciada. ${ }^{8} \mathrm{Na}$ maioria dos relatos, evidencia-se a crença na força divina. A fé, para as famílias, tem um importante papel no equilíbrio emocional, na aceitação das atividades e proporciona força para continuar lutando. Além disso, a fé e a espiritualidade são recursos poderosos que contribuem para o fortalecimento dos vínculos familiares.

Ah! Deus, em oração, tenho muita fé [...] mas meus filhos também me dão muita força (Laura, avó do Rafael).

Busco força comigo mesmo. Peço a Deus para ajudar ele a superar tudo isso. Tenho que ser forte [...] meu pai, onde estiver, também está olhando por ele (Eva, mãe do Miguel).

No processo de adaptação para lidar com a doença, os familiares da criança com câncer buscam superar os efeitos do tratamento, manter a integridade da família e o bem-estar emocional, estabelecendo suporte e buscando por significado espiritual. ${ }^{12} \mathrm{~A}$ espiritualidade e a fé estão presentes na vida das pessoas, principalmente nas situações mais difíceis. ${ }^{13}$ Neste momento de sofrimento e de luta, a fé é vista como um remédio muito poderoso para os familiares, pois eles mantêm a esperança em busca de um significado e de confiança em um ser superior. Isso propicia fortalecimento e serenidade para aceitar a doença. ${ }^{14}$

\section{As redes de apoio encontradas pela família}

O enfermeiro, ao conhecer as redes de apoio da família da criança com câncer, tem subsídios para intervir em situações subsequentes da doença e do tratamento quimioterápico, como, por exemplo, problemas relacionados aos aspectos psicossocial e emocional, além dos efeitos adversos da terapêutica. Devido à complexidade de cuidar nesse processo e contexto, a enfermagem necessita realizar um trabalho multidisciplinar, integrando outras áreas de conhecimento, a fim de contribuir para um cuidado humanizado junto a essas famílias. 
O enfermeiro desempenha um papel importante, quando é um vínculo apoiador para os integrantes da família das crianças com câncer. As ações que compõem este papel de fornecer apoio são parte do cuidado integral fornecido pelos enfermeiros. ${ }^{15}$ Dessa forma, para que as equipes de enfermagem e de saúde possam contribuir substancialmente no percurso do estar com câncer, se faz necessário que conheçam e integrem a rede social dessas famílias. Nesse sentido, há que se reconhecer que o sistema familiar e sua rede social, associados ao cuidado de enfermagem realizado à família da criança com câncer, se constituem em importantes estratégias para lidar com as diversas situações impostas.

A família, neste estudo, é analisada como um microssistema e em sua interação com seu mesossistema (família, hospital, igreja, comunidade). Nessa condição, ela é capaz de formar vínculos apoiadores que ocorrem quando os papéis, atividades e díades em que a pessoa de ligação se envolve, nos dois ambientes, encorajam o desenvolvimento da confiança mútua, de uma orientação positiva, de um equilíbrio evolutivo, de poder responsivo à ação em favor da pessoa em desenvolvimento. ${ }^{4}$

Tenho uma amiga, e converso muito com ela, exponho meus problemas, ela me compreende me aconselha [...] Converso com minha filha, dou força para ela se manter calma e passar calma para o filho, pois ele precisa dela. Quando eu consigo passar isso, fico mais tranquila também (Laura, avó do Rafael).

Tenho boa relação com todos aqui, mas nós criamos um vínculo tão grande, que só me animo a sair de perto do Gabriel quando você [pesquisadora] está aqui no quarto (Alice, mãe do Gabriel).

Desabafei muito com a psicóloga, principalmente no início, quando eu não sabia o que o Miguel tinha (Eva, mãe do Miguel).

O apoio que precisei, encontrei na minha família (João, pai do Miguel).

Ao analisarmos os relatos, evidenciamos que surge nesse contexto o que consideramos como principal, o vínculo apoiador dos integrantes das famílias, que se constituiu através dos profissionais de saúde e amigos que acompanharam o percurso da doença e do tratamento. O vínculo se forma através de ligações afetivas e também de proximidade. E quando estão presentes as manifestações de afeto, ou seja, sentimento de amor, vontade de estar junto, tocar carinhosamente e demonstrar admiração, respeito, ocorre então um fortalecimento dos vínculos entre os membros da família e estes se sentem mais ligados emocionalmente, revelando sensação de bem-estar. ${ }^{16}$
Os vínculos apoiadores mantidos ou formados pelas famílias, tanto no ambiente intrafamiliar como extrafamiliar, contribuem para o desenvolvimento e o cuidado das mesmas, assim como para a outra pessoa que participa dessa interação. Nesse sentido, a família é um microssistema, que se inter-relaciona com outros sistemas; é uma organização social e econômica incrustada na rede de relações, ocupando papéis em vários sistemas sociais, apoiando e cuidando de seus indivíduos integrantes. Por isso, pode ser um vínculo apoiador para os mesmos. ${ }^{17}$

Os pais, ao priorizarem a atenção ao filho doente, além de se distanciarem da unidade familiar, distanciam-se dos afazeres domésticos. Assim, para realizar as atividades do cotidiano, na maioria das vezes necessitam do auxílio de familiares e/ou vizinhos. Quando a família não possui uma rede de apoio em situação de doença e da hospitalização, as dificuldades somam-se às do cotidiano. ${ }^{9}$ Nesse sentido, constatamos, nos relatos, aspectos significativos que se compreende como rede social de apoio.

O meu filho mais velho é que ficou encarregado de pagar as contas e tocar a oficina, mas os amigos também se ofereceram (João, pai do Miguel).

Bastante gente apareceu para dar apoio, o pessoal da igreja, a família do meu marido, estão sempre perguntando, oferecendo ajuda (Alice, mãe do Gabriel).

Minha patroa, ela me ajuda muito, principalmente na questão de dinheiro, porque, quando chega nessas horas [doença], a gente precisa mais. E também apoio, ela foi a pessoa que mais se aproximou desde a descoberta da doença (Laura, avó de Rafael).

Ocuidado se inicia na família nuclear, se amplia para a família expandida, e é complementado pela rede social com vizinhos e amigos, podendo chegar ao sistema oficial de saúde. ${ }^{18}$ Os familiares mais próximos são vistos como importantes fontes de apoio, pois, em momentos críticos, são eles que dividem o sofrimento com os pais da criança adoecida.

Diante da doença e do tratamento da criança com câncer, a família tem que lidar com um mundo diferente do seu, o hospital, cuja organização, dinâmica e lógica é muito diferente do seu cotidiano. Assim, a família, ao viver a facticidade da doença do filho, mostra-se solidária à criança e às outras famílias que vivenciam a mesma realidade. ${ }^{11}$ Esta rede de solidariedade pode ser observada no seguinte relato: adoro ajudar as mães novatas, eu me sinto bem fazendo isso [...] também busco forças com as outras mães, vejo que não é só comigo que acontece, pergunto como foi que tudo iniciou [...] (Luana, mãe do Rafael).

A interação que ocorre entre Luana e as outras mães pode proporcionar maior conhecimento e, 
através dessa ajuda mútua, futuramente se tornará um vínculo apoiador. Assim, através da percepção e do compartilhamento das experiências e do sofrimento de outras famílias que vivenciam o câncer na criança, surge o interesse em ajudar e cuidar do próximo e, a partir desse processo, formar-se-á uma extensa rede solidária fortalecida.

\section{Vínculos fragilizados pela doença}

A relação familiar não ocorre apenas através de vínculos integrativos. Em muitas famílias, o adoecer de um membro pode gerar desadaptações, assim o envolvimento não acontece na mesma dimensão para todos, e o estabelecimento dos vínculos pode não ser homogêneo. Quando um integrante da família fica doente, todos os outros são afetados, o que com frequência gera tensão, estresse e fadiga dentro do contexto familiar, principalmente entre aqueles responsáveis pela realização dos cuidados. Dependendo do problema de saúde, as pessoas podem ter necessidade de fazer adaptações em seu estilo de vida ou reestruturá-la. ${ }^{19}$

Percebe-se que a capacidade de lidar com a doença não é igual para todos os membros da família. Mesmo que exista um grau de consanguinidade próxima, os vínculos com a pessoa doente não se estabelecem de uma forma igualitária.

No meu modo de ver, eu achava que ele [marido] tinha que estar mais presente... eu até entendo o trabalho dele, mas, quando a gente quer alguma coisa, a gente arruma um jeito. Se eu consegui [...] Às vezes eu falo para ele vir! Avisei quando o Gabriel ia para a cirurgia, mas ele fez de tudo para não vir (Alice, mãe do Gabriel).

Evidencia-se que a doença grave na criança pode fragilizar os vínculos anteriormente estabelecidos, porque ela gera uma série de sentimentos e situações que podem desestabilizar uma família. A resposta do pai é frágil, e a maneira de lidar com a situação parece ser de fuga. Esse comportamento é avaliado pela esposa com certa recriminação, pois, no seu entendimento, apoiar o ser doente é estar junto, é querer ir ao encontro, é movimentar-se na direção do outro.

As famílias que vivenciam o risco de morte de um filho conhecem a dimensão da experiência. Tão mais difícil e sofrido será, quão menor sejam a ajuda e o apoio solicitados ou espontâneos, o que inclui apoio entre o casal, a ajuda de familiares, amigos, colegas da instituição hospitalar e religiosa. ${ }^{9}$

$\mathrm{O}$ câncer infantil gera mudanças afetivas e instrumentais em um curto tempo, exigindo da família uma mobilização mais rápida na sua ca- pacidade de administrar a crise que vivencia, bem como a sobrecarga da realização do cuidado, que reduz o tempo livre do cuidador familiar para si e para os demais familiares. Essa realidade pode ocasionar, inclusive, problemas de relacionamento entre casais, entre pais e filhos e outros parentes, assim como o convívio cotidiano com a dor, o sofrimento e o fantasma da morte são uma realidade de manejo difícil por parte dos familiares. ${ }^{20}$

A adversidade da situação não só converge para religiosidade e espiritualidade, mas também surgem momentos de descrenças, e a fé em períodos de crise fica abalada. O que pode ser visto no relato de Ema, onde se pode dizer que esse vínculo fragilizou-se: tem gente que diz que na crise reza mais, busca mais. Mas eu não! Eu fico tão abalada e descrença (Ema, tia do Gabriel).

A fé no momento de crise também sofre um abalo, e a infelicidade sentida revela preocupações sobre a distribuição injusta de sofrimento no mundo. Isso muitas vezes gera uma confrontação com o conceito de um Deus bondoso que proporciona força, esperança e dá o significado para a vida. ${ }^{14} \mathrm{As}$ pessoas, quando estão passando por um período de sofrimento, esperam contar com o apoio da família, vizinhos, comunidade, igreja e, justo neste momento em que mais precisam, sentem-se esquecidas.

Desliguei-me da igreja. No momento que eu mais precisei, eles não estavam ali! O apoio que digo era de estar ao lado, uma força de encorajamento. Muita gente não me apoiou (Luana, mãe do Rafael).

A família, quando enfrenta uma situação de doença, tenta buscar resposta para entender tudo o que está ocorrendo, no contexto em que vive, com as pessoas que interage e, na maioria das vezes, inicia a questionar a fé em Deus. Diante disso, a família vai buscar apoio ou espera ser apoiada por pessoas que compartilhem da mesma crença, com o objetivo de lhe ajudar a entender toda essa situação e para lhe fazer companhia neste período tão difícil que é o de vivenciar o câncer e o tratamento.

\section{CONSIDERAÇÕES FINAIS}

Cada família é única e apresenta dinâmicas diferentes de organização frente à vivência de câncer. Neste estudo, as famílias se revelaram como seres autênticos assumindo o adoecer da criança e buscando as melhores estratégias para lidar com a doença, assim como para seu núcleo familiar. Evidenciamos que a procura de caminhos para superar as dificuldades encontradas nem sempre demonstrou homogeneidade nas famílias. 
Enquanto algumas tinham flexibilidade e estavam abertas para encontrar soluções favoráveis para essa situação de doença, outras apresentavam dificuldades de trabalhar com as questões inerentes que surgiram frente ao adoecer.

Salientamos que a principal rede de apoio das famílias são os familiares, mas o apoio recebido de amigos, vizinhos e colegas de trabalho também foi enfatizado como indispensável para superar as dificuldades. Nesse contexto, a religiosidade aparece como estratégia das pessoas envolvidas no cuidado à criança com câncer, para lidar com as situações difíceis, as mudanças em seu cotidiano, mas sempre acreditando na recuperação da criança e com a esperança de cura.

Entretanto, destacamos que, mesmo possuindo uma boa rede social, muitos vínculos familiares e sociais podem ser fragilizados pela doença. Consideramos que os profissionais de enfermagem podem atuar no fortalecimento dos vínculos apoiadores e da rede social, influenciando e sendo influenciados pela família da criança com câncer, buscando conhecer a natureza das relações das pessoas envolvidas com o grupo familiar.

Para finalizar, pontuamos a relevância de novos estudos que envolvam maior número de entrevistados a fim de aprofundar outras dimensões que este estudo não se propôs a investigar.

\section{REFERÊNCIAS}

1. Muniz RM, Dutra MG. O cliente em tratamento quimioterápico: a família vivenciando o cuidado. Fam Saúde Desenv. 2003 Mai-Ago; 5(2):125-32.

2. Souza AIJ, Erdmann AL. A criança com diagnóstico de câncer: revisitando o caminho das políticas de atendimento. Rev Gaúcha Enferm. 2003 Abr; 24(1):23-33.

3. Ministério da Saúde (BR). Particularidades do Câncer Infantil [página na Internet]. Rio de Janeito (RJ): INCA; 2009 [acesso 2009 Out 05]. Disponível em: http://www.inca.gov.br/conteudo

4. Bronfenbrenner U. A ecologia do desenvolvimento: experimentos naturais e planejados. Porto Alegre (RS): Artes Médicas; 1996.

5. Wright L, Leahey M. Enfermeiras e famílias: um guia para avaliação e intervenção na família. $4^{a}$ ed. São Paulo (SP): Roca; 2009.

6. Nascimento LC, RochaSMM, Hayes VE. Contribuição do ecograma e do ecomapa para o estudo de famílias em enfermagem pediátrica. Texto Contexto Enferm. 2005 Abr-Jun; 14(2):280-6.
7. Minayo MCS. O desafio do conhecimento: pesquisa qualitativa em saúde. São Paulo (SP): Hucitec; 2007.

8. Bielemann VLM. Uma experiência de adoecer e morrer em família. In: Elsen I, MarconSS, Silva MRS, organizadoras. O viver em família e a interface com a saúde e a doença. $2^{a}$ ed. Maringá (PR): Eduem; 2004. p.199-215.

9. Ribeiro NRR. A família enfrentando a doença grave na criança. In: Elsen I, Marcon SS, Silva MRS, organizadoras. O viver em família e a interface com a saúde e a doença. $2^{a}$ ed. Maringá (PR): Eduem; 2004. p.183-98.

10. FaquinelloP,Higarashi IH, MarconSS. Oatendimento humanizado em unidade pediátrica: percepção do acompanhante da criança hospitalizada. Texto Contexto Enferm 2007 Out-Dez; 16(4):609-16.

11. Motta MGC. O ser doente no tríplice mundo da criança, família e hospital: uma descrição fenomenológica das mudanças existenciais [tese]. Florianópolis: Universidade Federal de Santa Catarina; 1997.

12. Nascimento LC, Rocha SMM, Hayes VH, Lima RAG. Crianças com câncer e suas famílias. Rev Esc Enferm USP. 2005 Dez; 39(4):469-74.

13. Beck ARM, Lopes MHBM. Cuidadores de crianças com câncer: aspectos da vida afetados pela atividade de cuidador. Rev Bras Enferm. 2007 Nov-Dez; 60(6):670-5.

14. Teixeira JJV, Lefèvre F. Significado da intervenção médica e da fé religiosa para o paciente idoso com câncer. Ciênc Saúde Colet. 2008 Jul-Ago; 13(4):1247-56.

15. Pedro ICS, Galvão CM, Rocha SMM, Nascimento LC. Apoio social e famílias de crianças com câncer: revisão integrativa. Rev Latino-am Enfermagem [online]. 2008 Mai-Jun [acesso 2010 Abr 17]; 16(3): Disponível em: http://www.scielo.br/pdf/rlae/v16n3/pt_23.pdf

16. Elsen I. Cuidado Familial: uma proposta inicial de sistematização conceitual. In: Elsen I, Marcon SS, Silva MRS, organizadoras. O viver em família e a interface com a saúde e a doença. $2^{\mathrm{a}}$ ed. Maringá (PR): Eduem; 2004. p.19-28.

17. Schwartz E. O viver, adoecer e o cuidar das famílias de uma comunidade rural do extremo Sul do Brasil. In: Elsen I, Marcon SS, Silva MRS, organizadoras. O viver em família e a interface com a saúde e a doença. $2^{a}$ ed. Maringá (PR): Eduem; 2004. p.79-93.

18. Budó MLD, Saupe R. Modos de cuidar em comunidades rurais: a cultura permeando o cuidado de Enfermagem. Texto Contexto Enferm. 2005 AbrJun; 14(2):177-85.

19. Carter B, McGoldrick M. As mudanças no ciclo de vida familiar: uma estrutura para a terapia familiar. $2^{\mathrm{a}}$ ed. Porto Alegre (RS): Artes Médicas; 2001.

20. Comaru NRC, Monteiro ARM. O cuidado domiciliar à criança em quimioterapia na perspectiva do cuidador familiar. Rev Gaúcha Enferm. 2008 Set; 29(3):423-30.

Recebido em: 21 de setembro de 2009 Aprovação final: 13 de abril de 2010 